\title{
Hepatoprotective Activity of Methanolic Extract of Whole Plant of Pulicaria Wightiana L. against Carbon Tetrachloride and Paracetamol -Induced Hepatotoxicity in Rats
}

\author{
S. Nelson Kumar ${ }^{* 1}$, K. Ravindra Reddy ${ }^{1}$, K. B. Chandra Sekhar ${ }^{2}$, \\ J. P. Yanadaiah ${ }^{1}$, Rakhal Chandra Das ${ }^{3}$. \\ ${ }^{I}$ Department of Pharmacology, P. Rami Reddy Memorial College of Pharmacy, Kadapa (DT), Andhra Pradesh, \\ India. \\ ${ }^{2}$ Department of Pharmaceutics, P. Rami Reddy Memorial College of Pharmacy, Kadapa (DT), Andhra \\ Pradesh, India. \\ ${ }^{3}$ Department of Chemistry, JNTUA, Ananthapuramu, Anantapur (DT), Andhra Pradesh, India. \\ ${ }^{4}$ Department of Pharmacognosy, P. Rami Reddy Memorial College of Pharmacy, Kadapa (DT), Andhra \\ Pradesh, India. \\ ${ }^{5}$ University Department of pharmaceutical sciences, Utkal university, Odisha, India
}

\begin{abstract}
Natural remedies from medicinal plants are considered to be effective and safe alternative treatment for liver injury. The present study was conducted to evaluate the hepatoprotective activity of methanolic extract of whole plant of Pulicaria wightiana in wistar rats. The studies were conducted using the two popular inducing agents Paracetamol $(2 \mathrm{~g} / \mathrm{kg}$, p.o.) in $1 \% \mathrm{NaCMC}$ and Carbon tetrachloride $(1 \mathrm{ml} / \mathrm{kg})$. Silymarin $(100 \mathrm{mg} / \mathrm{kg}$, p.o.) was used as reference drug in the respective models. The effect was estimated by measuring the enzymatic levels and histo- pathological studies. The methanolic extract of whole plant of Pulicaria wightiana has shown very significant hepatoprotection against both Paracetamol and $\mathrm{CCl}_{4}$ - induced hepatotoxicity study models in wistar rats. This was evidenced by marked reduction in marker enzymes in serum. Histopathological studies also confirmed the hepatoprotective nature of the extract.
\end{abstract}

Keywords: Carbon tetrachloride, flavanoids, hepatoprotective, paracetamol, Pulicaria wightiana.

\section{Introduction}

Liver is the vital organ of metabolism and excretion. It is continuously and variedly exposed to xenobiotics because of its strategic placement in the body. Hepatic injury is associated with distortion of metabolic functions, thus liver ailments remain as one of the serious health problems ${ }^{(1)}$. Drug induced liver injury is a major health problem that challenges not only health care professionals but also the pharmaceutical industry and regulatory agencies. Drug induced liver injury is responsible for 5\% of all hospital admissions and $50 \%$ of all liver failure ${ }^{(2)}$. More than 900 drugs have been concerned in causing injury to liver and it is the most familiar reason for a medicine to be withdrawn from the market. According to the United States Acute Liver Failure Study Group, drug-induced liver injury accounts for more than 50\% of acute liver failure, including liver damage caused by overdose of acetaminophen and idiosyncratic liver injury triggered by other drugs. Chemicals frequently cause subclinical injury to liver that can be detected by estimating liver enzyme levels. Modern medicines have little to offer for alleviation of hepatic diseases and it is chiefly the plant based preparations which are employed for their treatment of liver disorders. However, there are not enough drugs available for the treatment of liver disorders. Recently, many folk remedies from plant origin are being evaluated for its possible antioxidant and hepatoprotective effects against different chemical-induced liver damage in experimental animals ${ }^{(3,4)}$

Pulicaria wightiana (Sontiki) plant belonging to the family Asteraceae. Leaves are smaller towards the top. Flower-heads are yellow, $2-4 \mathrm{~cm}$ across, arising singly on leafy stalks, $10-20 \mathrm{~cm}$ long, at the end of branches. The stalks are hollow, enlarged upwards. Ray florets are 1.5-2 cm long, 2-3 mm wide, 3 -toothed at the tip. Sesquiterpenoids, diterpenoids and flavonoids were reported to find in the plant ${ }^{(5,6)}$.

\subsection{Plant material}

\section{Materials And Methods}

Whole plant of Pulicaria wightiana was collected during flowering season from Utukur village, Kadapa district, Andhra Pradesh, India. The plant was authenticated by Dr. Madhava chetty, Taxonomist, S.V. University, Tirupathi, India. The collected whole plant were washed immediately and dried at $50^{\circ} \mathrm{C}$ for a week, powdered mechanically, sieved (10/44) and stored in air-tight containers. 
Hepatoprotective Activity of Methanolic Extract of Whole Plant of Pulicaria Wightiana L. against ..

\subsubsection{Preparation of Extracts}

About $2000 \mathrm{~g}$ of the powdered material was subjected to soxhlation and exhaustively extracted with methanol for $48 \mathrm{~h}$. The solvent was distilled off at low temperature under reduced pressure using rotary flash evaporator (buchi, flawil, Switzerland). The semisolid mass obtained was dried in an oven at $40^{\circ} \mathrm{C}$, powdered, labeled as MEPW and stored in desiccator.

\subsection{Chemicals}

Carbon tetrachloride was procured from S.D. Fine Chemicals Ltd. (India). Silymarin was obtained as gift sample from Ranbaxy (Devas, India). Standard kit of SGPT, SGOT, ALP and bilirubin were obtained from Jain Scientific Industries, Moradabad, India. All other reagents used were of analytical grade.

\subsection{Phytochemical investigation}

Phytochemical tests were carried out to find out the presence of phytoconstituents viz flavanoids, steroids, carbohydrates, phenolics etc and the results are shown in Table: 1

\subsection{Experimental Animals}

Wistar rats (150-200 g) were used in this experiment. They were housed in standard cages by maintaining a temperature of $22 \pm 2^{\circ} \mathrm{C}$ at 12:12 hours light dark cycle. The animals were provided with pellet diet and water ad libitum. The experimental procedures were carried out in strict compliance with the ethical guidelines for investigations of experimental pain in conscious animal framed by the Institutional Animal Ethical Committee rules and regulations in this institute.

\subsubsection{Acute toxicity studies}

Acute oral toxicity studies were conducted to determine the $\mathrm{LD}_{50}$ cut off value $(\mathrm{mg} / \mathrm{kg}$ body weight) as per the OECD Guideline - 425

\subsubsection{Biochemical estimation of markers of oxidative stress}

SOD activity was determined according to previous report ${ }^{(7)}$. CAT activity was determined from the rate of decomposition of $\mathrm{H}_{2} \mathrm{O}_{2}$ by the reported method ${ }^{(8)}$. GPX activity was determined by measuring the decrease in GSH content after incubating the sample in the presence of $\mathrm{H}_{2} \mathrm{O}_{2}$ and $\mathrm{NaN}_{3}{ }^{\left({ }^{9}\right)}$. Glutathione reductase activity was assayed according to previous reports ${ }^{(10)}$. Protein content in the tissue was determined by earlier method reported ${ }^{(11)}$, using bovine serum albumin (BSA) as the standard.

\subsubsection{Histopathological study}

The liver was removed and stored immediately in 10 percent formalin. The tissue was subsequently put in paraffin. Thin $(5 \mu \mathrm{m})$ sections were drawn using a microtone and then stained with hematozylin and eosin and mounted in neutral di-styrene-dibutyl propylene (DPX) medium and examined using photo microscopy ${ }^{(12)}$.

\subsubsection{Assessment of hepatoprotective activity}

A toxic dose or repeated doses of a known hepatotoxin such as carbon tetrachloride, paracetamol, thioacetamide, rifampicin, alcohol, D-galactosamine, allyl-alcohol etc., are administered to induce liver damage in experimental animals ${ }^{(13)}$. If the hepatotoxicity produced by the toxin is prevented or reduced, then the test substance is considered as an effective hepatoprotective agent. In the present investigation, rats (n=6) were randomized into following groups and the pharmacological investigation was carried using carbon tetrachloride and paracetamol as inducing agents and the test MEPW at dose levels of 200 and $400 \mathrm{mg} / \mathrm{kg}$ as hepatoprotective agent.

1) Group I - $1 \%$ w/v NaCMC per orally for 21 days.

2) Group II - $\mathrm{CCl}_{4}(1 \mathrm{ml} / \mathrm{kg})$ administered by i.p $+1 \% \mathrm{w} / \mathrm{v} \mathrm{NaCMC}$ per orally for 21 days.

3) Group III - Paracetamol ( $2 \mathrm{~g} / \mathrm{kg})$ in $1 \% \mathrm{NaCMC}$ per orally for 21 days.

4) Group IV- $\mathrm{CCl}_{4}(1 \mathrm{ml} / \mathrm{kg})$ administered by i.p + MEPW $(200 \mathrm{mg} / \mathrm{kg})$ in $1 \% \mathrm{w} / \mathrm{v} \mathrm{NaCMC}$ per orally for 21 days.

5) Group V- $\mathrm{CCl}_{4}(1 \mathrm{ml} / \mathrm{kg})$ administered by i.p + MEPW $(400 \mathrm{mg} / \mathrm{kg})$ in $1 \% \mathrm{w} / \mathrm{v} \mathrm{NaCMC}$ per orally for 21 days

6) Group VI- Paracetamol ( $2 \mathrm{~g} / \mathrm{kg})$ and MEPW $(200 \mathrm{mg} / \mathrm{kg})$ in $1 \% \mathrm{w} / \mathrm{v} \mathrm{NaCMC}$ per orally for 21 days.

7) Group VII- Paracetamol (2 g/kg) and MEPW (400mg/kg) in 1\% w/v NaCMC per orally for 21 days.

8) Group VIII- $\mathrm{CCl}_{4}(1 \mathrm{ml} / \mathrm{kg})$ administered by i.p and Silymarin $(100 \mathrm{mg} / \mathrm{kg})$ in $1 \% \mathrm{w} / \mathrm{v} \mathrm{NaCMC}$ per orally for 21 days.

9) Group IX- Paracetamol ( $2 \mathrm{~g} / \mathrm{kg})$ and Silymarin $(100 \mathrm{mg} / \mathrm{kg})$ in $1 \% \mathrm{w} / \mathrm{v}$ NaCMC per orally for 21 days.

Treatment with plant extract was started after $24 \mathrm{hrs}$ of administration of inducing agents. After 21 days of such treatment, rats were sacrificed by cervical dislocation. Blood was collected and serum was separated by allowing the blood samples to coagulate for $30 \mathrm{~min}$ at $37^{\circ} \mathrm{C}$ followed by centrifugation ( $3000 \mathrm{rpm}$ for $15 \mathrm{~min}$ ) and subjected for determination of biochemical parameters like total bilirubin, SGPT, SGOT and ALP ${ }^{(14)}$. Liver was dissected out, washed with ice cold Phosphate Buffer Saline (PBS) (0.1 M, pH 7.4) and 10\% tissue homogenate used for different biochemical analysis. A part of the liver was used for histopathological studies. 


\section{Stastical Analysis}

The results are expressed as Mean \pm SEM of six animals from each group. The data were evaluated by one-way ANOVA followed by Tukey's multiple comparison tests. *P values $<0.05$ was considered statistically significant.

\subsection{Preliminary phytochemical screening}

\section{Results}

The various phytoconstituents present in different extracts were given in Table 1. MEPW showed significant amounts of flavanoids and triterpenes.

\subsection{Acute toxicity studies}

The MEPW did not exhibit any toxic effects up to $4000 \mathrm{mg} / \mathrm{kg}$ body weight on oral administration. Body weight before and after administration were noted and any changes in skin, fur, eyes, mucous membranes, respiratory, circulatory, autonomic, central nervous system, somatomotor activity, behavioral pattern were observed, sign of tremors, convulsions, salivation, diarrhea, lethargy, sleep and coma were seen. The onset of toxicity and signs of toxicity were not seen in the rats up to $72 \mathrm{hr}$ of observation period. This indicates the safety of extract.

\subsection{Biochemical parameters}

Rats treated with carbon tetrachloride and paracetamol showed a significant hepatic damage as observed from elevated levels of hepato-specific enzymes as well as severe alteration in different liver parameters. SGPT, SGOT, and total bilirubin in serum were increased in carbon tetrachloride and paracetamol intoxicated control animals. Treatment with the methanolic extract of Pulicaria wightiana caused significant protection against paracetamol and $\mathrm{CCl}_{4}$-induced increase in serum enzyme levels and bilirubin in a dose responsive manner. Similarly, LP, SOD, CAT and GSH contents were estimated from liver homogenate and MEPW showed significant protection against both paracetamol and $\mathrm{CCl}_{4}$ induced liver damage.

\subsection{Histopathological Studies}

Histhopatological examination of liver sections of control group showed normal cellular architecture with distinct hepatic cells, sinusoidal spaces and central veins. Disarrangement of normal hepatic cells with centrilobular necrosis, vacuolization of cytoplasm and fatty degeneration were observed in paracetamol and $\mathrm{CCl}_{4}$ intoxicated animals. The liver sections of the rats treated with methanolic extract of Pulicaria wightiana and standard drugs followed by paracetamol and $\mathrm{CCl}_{4}$ intoxication showed a sign of protection as it was evident the absence of necrosis and vacuoles.

\section{Discussion}

Carbon tetrachloride and paracetamol are the well known hepato-destructive agents that are widely used to induce acute-toxic liver injury in laboratory animals. The changes associated with $\mathrm{CCl}_{4}$-induced hepatic damage are similar to that of acute viral hepatitis. The hepatotoxicity of $\mathrm{CCl}_{4}$ has been reported to be due to its biotransformation by cytochrome P-450 system to produce trichloroethylene free radicals. These free radicals may again react with oxygen to form trichloroethylene peroxy radicals, which exert their action on lipids membrane of endoplasmic reticulum to evoke lipid peroxidation ${ }^{(15)}$. Overdose of paracetamol causes a potentially fatal, hepatic centrilobular necrosis. The hepatotoxicity of paracetamol has been attributed to the formation of a toxic metabolite, N-acetyl-p-benzoquinoneimine (NAPQI) by the action of cytochrome P4502E1 (16).

In the present investigation, $\mathrm{CCl}_{4}$ and paracetamol administration resulted in elevated activities of AST, ALT and ALP in serum against their respective control values. Similarly, serum bilirubin level was also found to be increased significantly as a result of $\mathrm{CCl}_{4}$ and paracetamol toxicity. On the other hand, total serum protein level was lowered in response to $\mathrm{CCl}_{4}$ and paracetamol administration when compared with control. Abnormally higher activities of serum ALT, AST and ALP after $\mathrm{CCl}_{4}$ and paracetamol administration are an indication of the development of hepatic injury, which is responsible for leakage of cellular enzymes into the blood. When liver plasma membrane gets damaged, a variety of enzymes normally located in the cytosol are released into the circulation $^{(17)}$.

Oral administration of various doses of MEPW to $\mathrm{CCl}_{4}$ and paracetamol intoxicated rats resulted in gradual normalization of the activities of AST, ALT and ALP. This evidently suggests the protective effect of the extract in improving the functional integrity of liver cells. Serum bilirubin is considered as an index for the assessment of hepatic function and any abnormal increase indicates hepatobiliary disease and severe disturbance of hepatocellular architecture. $\mathrm{CCl}_{4}$ and Paracetamol administration resulted in increased serum bilirubin level, thereby suggesting severe hepatic injury and confirming the hepatotoxic nature of $\mathrm{CCl}_{4}$ and paracetamol. 
Treatment with MEPW significantly decreased the elevated level of total bilirubin in serum towards normalcy indicating its hepatoprotective efficacy.

Hepatic lipid peroxidation (LP), expressed as TBARS (thiobarbituric acid reacting substances), increased significantly in $\mathrm{CCl}_{4}$ and paracetamol toxicity. While, the activities of protective enzymes such as Superoxide dismutase (SOD) and catalase (CAT) and glutathione and glycogen content in liver tissue were lowered after paracetamol administration. Enhanced LP and reduced activities of SOD and CAT is an indication of generation of free radical stress as a mark of hepatic damage due to $\mathrm{CCl}_{4}$ and paracetamol toxicity. Marked reductions in the activities of these free radical scavenging enzymes, SOD and CAT, associated with $\mathrm{CCl}_{4}$ and paracetamol toxicity were significantly reversed to normal on oral feeding of MEPW in a dose dependent manner conferring the antilipid peroxidative ability to the extract.

$\mathrm{CCl}_{4}$ and Paracetamol induced damage of hepatocytes is also a reason behind decreased glycogen content of liver tissue. Significant increase in hepatic glycogen level was observed after administration of the extract indicating improvement in hepatic status. Histopathological examination of liver sections of the normal control group showed normal cellular architecture with distinct hepatic cells. However, distinct hepatic necrosis was noted after $\mathrm{CCl}_{4}$ and paracetamol administration with destruction of hepatic cells. MEPW treatment to such $\mathrm{CCl}_{4}$ and paracetamol intoxicated rats showed recovery of the hepatocytes from necrosis. This also suggests that the plant extract has a tremendous potential to reverse the changes induced by paracetamol toxicity back to normal.

The curative efficacy of MEPW was dose dependent as evidenced by gradual reversal of the altered values of various biochemical markers back to normal following oral administration. This may, probably be through promotional activation of antioxidative enzymes and regeneration of hepatocytes that restore the structural and functional integrity of liver. The protective effects due to treatment with Pulicaria wightiana extract strongly indicated the possibility of the extract being able to prevent and/or mitigate any leakages of marker enzymes into circulation, condition the hepatocytes to accelerate regeneration of parenchymal cells, and preserve the integrity of the plasma membranes and hence restore these enzymes levels ${ }^{(18)}$. Thus, the present investigation confirms the hepatoprotective action of Pulicaria wightiana against paracetamol induced hepatotoxicity in rats.

\section{Acknowledgement}

We are thankful to Management of P. Rami Reddy Memorial College of Pharmacy, Kadapa, A.P for the providing the all facilities for carried out this work.

\section{Figures and Tables}

Table - 1:

\begin{tabular}{|l|l|}
\hline Constituent & MEPW \\
\hline Alkaloids & \\
Mayer`s test & \\
Dragendorff's test & -- \\
Wagner`s test & -- \\
Hager`s test & - \\
Carbohydrates & - \\
Molish`s test & \\
Fehling`s test & +++ \\
Benedict'stest & ++ \\
Steroids & ++ \\
Libermann-Burchard test & + \\
Salkowski test & ++ \\
Saponins & ++ \\
Foam test & \\
Phenolic compounds & + \\
Ferric chloride test & \\
Shinoda test & ++ \\
Lead acetate test & ++ \\
Alkaline reagent test & + \\
& - \\
\hline
\end{tabular}

Qualitative phytochemical analysis of methanolic extract of Pulicaria wightiana (MEPW) +++ High, ++ Moderate, + Slight, - Negative 
Hepatoprotective Activity of Methanolic Extract of Whole Plant of Pulicaria Wightiana L. against ..

TABLE: 2

\begin{tabular}{|l|l|l|l|l|}
\hline Group & SGOT (IU/L) & SGPT ( IU/L) & ALP (KA Units) & Total Bilirubin (mg/dL) \\
\hline Group I & $97.37 \pm 5.89$ & $76 \pm 5.0$ & $165.2 \pm 7.31$ & $0.54 \pm 0.005$ \\
\hline Group II & $420.5 \pm 12.28^{\# \#}$ & $301 \pm 14^{\# \#}$ & $332.9 \pm 10.5^{\# \# \#}$ & $4.25 \pm 0.4^{\# \#}$ \\
\hline Group III & $409 \pm 9.7^{\# \#}$ & $286.4 \pm 9.3^{\# \#}$ & $321.9 \pm 8.5^{\# \#}$ & $3.9 \pm 0.7^{\# \# \#}$ \\
\hline Group IV & $129.8 \pm 8.5^{*}$ & $125 . .8 \pm 5.5^{* *}$ & $227.4 \pm 3.4^{* * *}$ & $1.2 \pm 0.04^{* *}$ \\
\hline Group V & $113.6 \pm 12.5^{* * *}$ & $97.6 \pm 5.7^{* *}$ & $198.3 \pm 5.5^{* *}$ & $0.74 \pm 0.04^{* * *}$ \\
\hline Group VI & $137.2 \pm 5.7^{* * *}$ & $129.8 \pm 8.7^{* * *}$ & $235.7 \pm 7.5^{* * *}$ & $1.5 \pm 0.09^{* *}$ \\
\hline Group VII & $116.9 \pm 9.5^{* * *}$ & $103.6 \pm 5.7^{* *}$ & $207.6 \pm 5.2^{* * *}$ & $0.9 \pm 0.02^{* *}$ \\
\hline Group VIII & $107 \pm 9.7^{* * *}$ & $89.5 \pm 8.6^{* *}$ & $187.5 \pm 5.17^{* *}$ & $0.7 \pm 0.04^{* * *}$ \\
\hline Group IX & $110.7 \pm 4.6^{* * *}$ & $91.2 \pm 4.8^{* *}$ & $192.1 \pm 6.5^{* *}$ & $0.9 \pm 0.05^{* * *}$ \\
\hline
\end{tabular}

Methanolic extract of Pulicaria wightiana (MEPW) on serum enzymatic activity in $\mathrm{CCl}_{4}$ and Paracetamol induced liver damage in rats $(n=6)$.

The results are expressed as Mean \pm SEM of six animals from each group. \# indicates $\mathrm{p}<0.05$, \#\# indicates $\mathrm{p}<0.01$ and \#\#\# indicates $\mathrm{p}<0.001$ when compared to normal. $*$ indicates $\mathrm{p}<0.05$, $* *$ indicates $\mathrm{p}<0.01$ and $* * *$ indicates $\mathrm{p}<0.001$ when compared to $\mathrm{CCl}_{4}$ and paracetamol intoxicated groups were evaluated by one-way ANOVA followed by Tukey's multiple comparison tests.

TABLE: 3

\begin{tabular}{|l|l|l|l|l|}
\hline Group & $\begin{array}{l}\text { LP }(\text { moles of } \\
\text { MDA } \\
\text { formed/mg } \\
\text { protein) }\end{array}$ & $\begin{array}{l}\text { SOD } \\
\text { (Units of } \\
\text { activity/mg } \\
\text { protein) }\end{array}$ & $\begin{array}{l}\text { CAT } \\
(\mu \text { moles of } \\
\text { H2O2 } \\
\text { Decomposed } / \mathrm{mg} \text { protein })\end{array}$ & $\begin{array}{l}\text { GSH } \\
\mu \mathrm{g} / \mathrm{mg} \\
\text { protein })\end{array}$ \\
\hline Group I & $28.16 \pm 0.81$ & $15.68 \pm 1.22$ & $116.24 \pm 2.25$ & $4.41 \pm 0.16$ \\
\hline Group II & $618.29 \pm 12.4 \# \#$ & $8.6 \pm 0.67 \# \#$ & $50.87 \pm 3.69 \# \#$ & $1.92 \pm 0.62 \# \#$ \\
\hline Group III & $712.9 \pm 24.5 \#$ & $8.39 \pm 0.64 \# \#$ & $61.22 \pm 4.18 \# \# \#$ & $2.08 \pm 0.88 \# \#$ \\
\hline Group IV & $223.7 \pm 4.72^{* *}$ & $11.93 \pm 1.02^{* * *}$ & $85.5 \pm 1.27^{* *}$ & $3.76 \pm 0.11^{*}$ \\
\hline Group V & $147.7 \pm 5.2^{* * *}$ & $12.27 \pm 0.9^{* *}$ & $96.7 \pm 1.54^{* * *}$ & $3.92 \pm 0.13^{* *}$ \\
\hline Group VI & $245.9 \pm 10.5^{* *}$ & $11.6 \pm 1.04^{* * *}$ & $95.7 \pm 1.5^{* * *}$ & $3.12 \pm 0.09^{* * *}$ \\
\hline Group VII & $121.5 \pm 1.9^{* *}$ & $12.76 \pm 0.9 * *$ & $103.2 \pm 1.27^{*}$ & $3.89 \pm 0.07 * *$ \\
\hline Group VIII & $118.6 \pm 2.81^{* *}$ & $13.52 \pm 0.92$ & $106.24 \pm 1.85^{* *}$ & $3.82 \pm 0.09 * *$ \\
\hline Group IX & $94.8 \pm 6.5^{* *}$ & $12.96 \pm 0.64 * *$ & $107.12 \pm 1.08^{* *}$ & $4.01 \pm 0.06^{* *}$ \\
\hline
\end{tabular}

Methanolic extract of Pulicaria wightiana (MEPW) on LP, SOD, CAT, GSH and Glycogen content in liver in rats $(n=6)$

The results are expressed as Mean \pm SEM of six animals from each group. \# indicates $\mathrm{p}<0.05$, \#\# indicates $\mathrm{p}<0.01$ and \#\#\# indicates $\mathrm{p}<0.001$ when compared to normal. * indicates $\mathrm{p}<0.05$, ** indicates $\mathrm{p}<0.01$ and $* * *$ indicates $\mathrm{p}<0.001$ when compared to $\mathrm{CCl}_{4}$ and paracetamol intoxicated groups were evaluated by one-way ANOVA followed by Tukey's multiple comparison tests.

Fig: 1

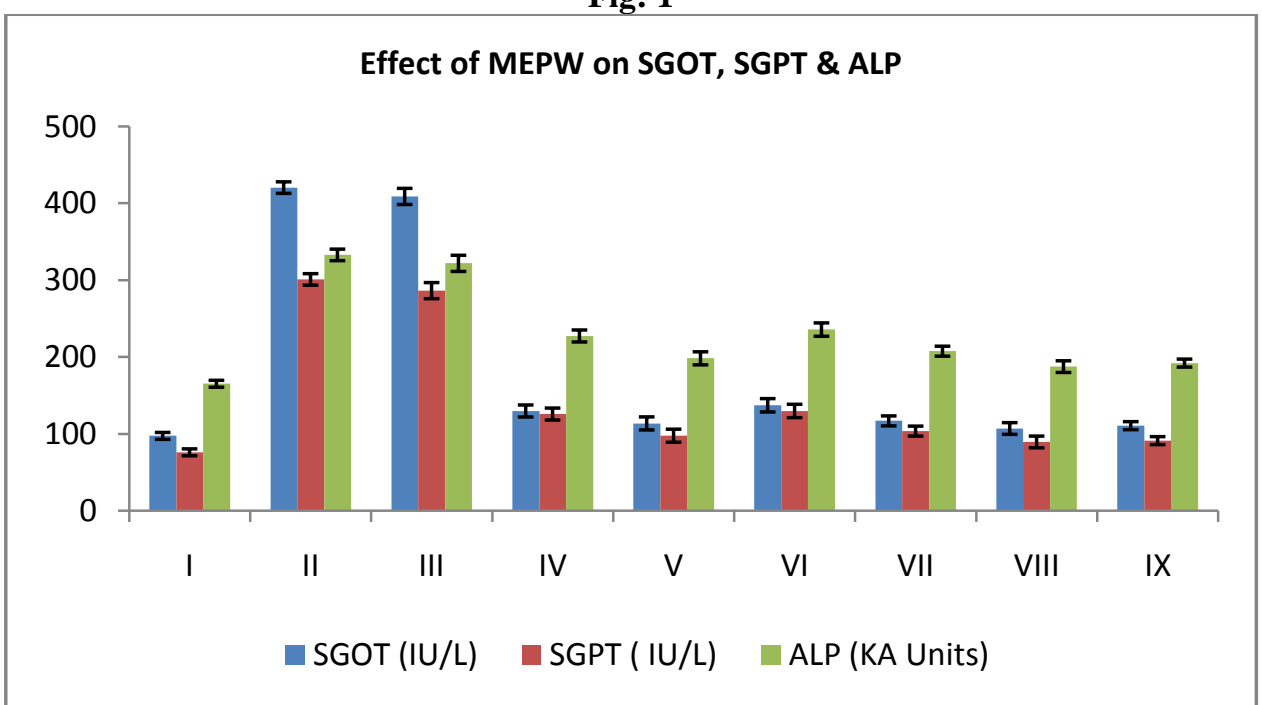

Effect of MEPW on SGOT, SGPT \& ALP levels in $\mathrm{CCl}_{4}$ and Paracetamol induced hepatotoxicity in rats. 
Fig:2

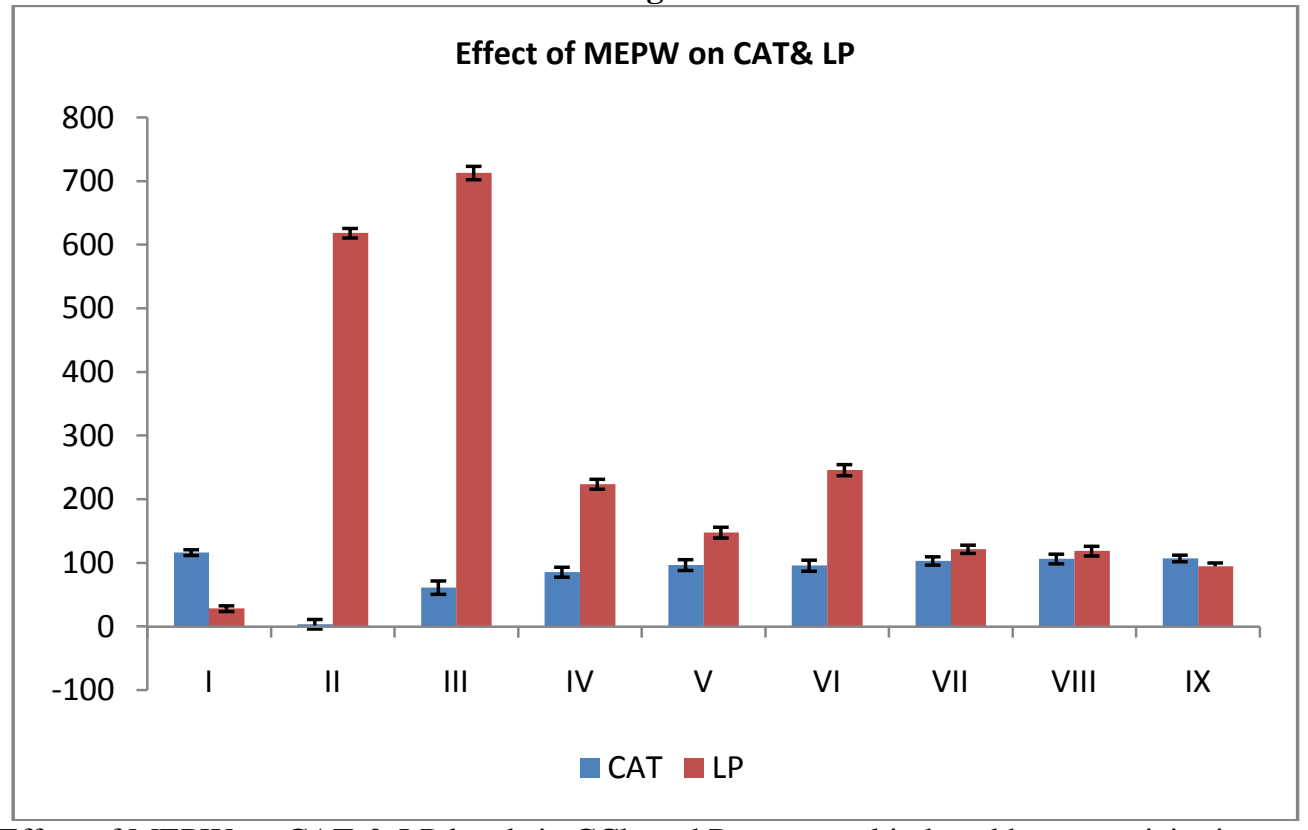

Effect of MEPW on CAT \& LP levels in $\mathrm{CCl}_{4}$ and Paracetamol induced hepatotoxicity in rats.

Fig:3

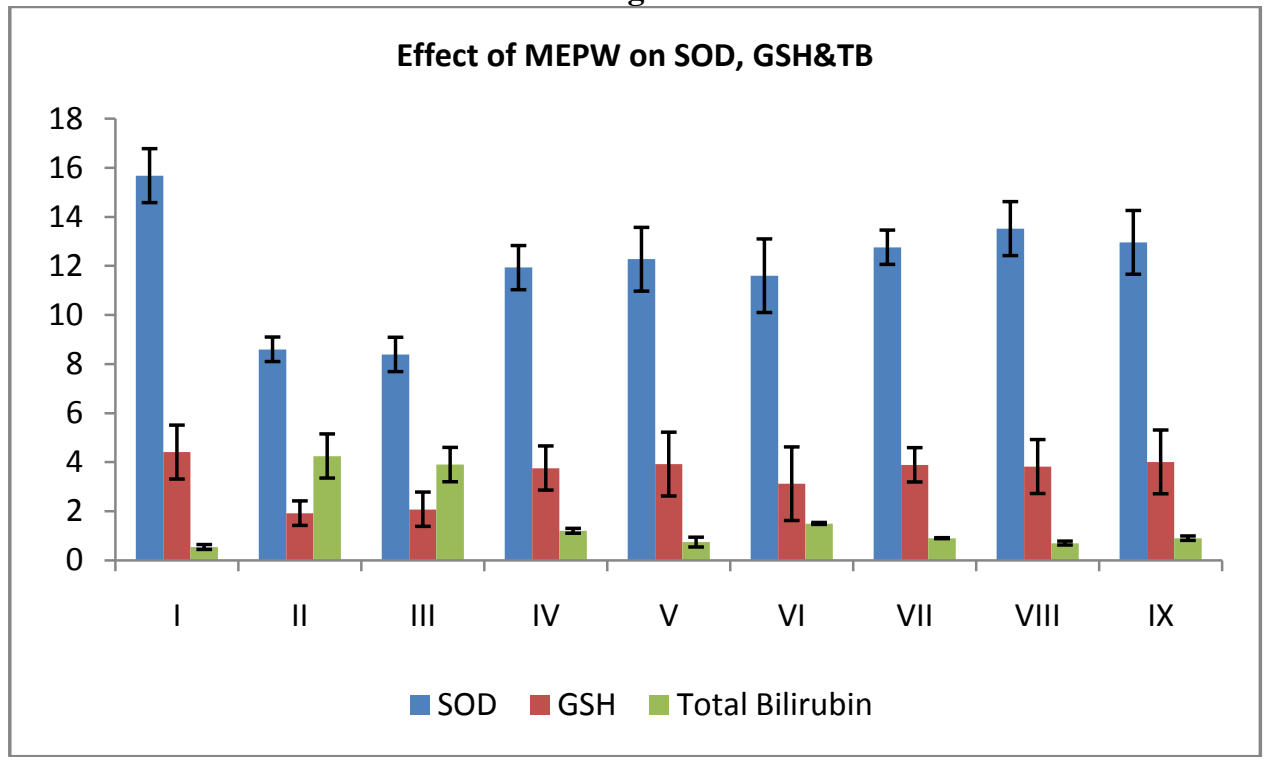

Effect of MEPW on SOD, GSH \& TB levels in $\mathrm{CCl}_{4}$ and Paracetamol induced hepatotoxicity in rats.

Figures

Microphotographs (10 x 40) of liver section taken from rats.

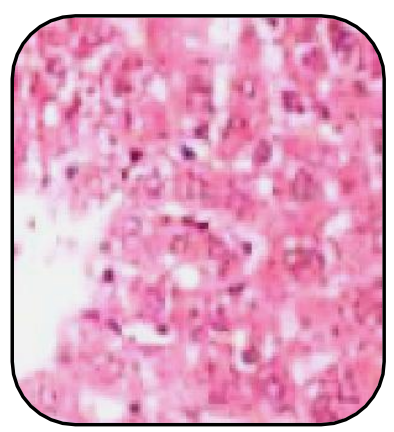

Group I

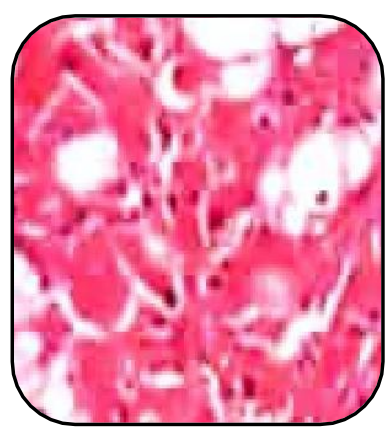

Group II

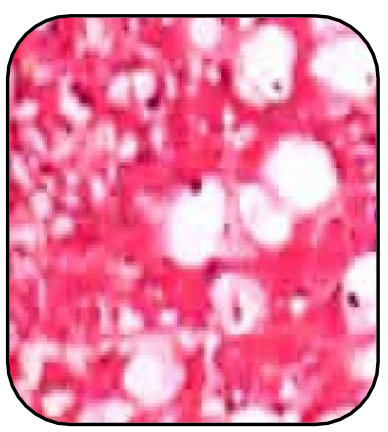

Group III 


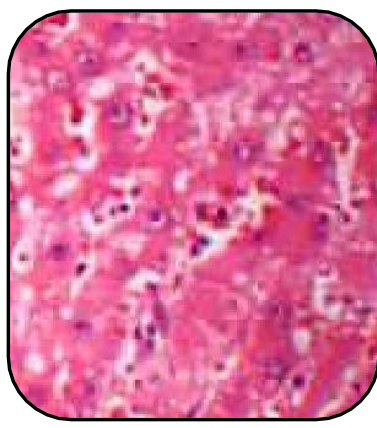

Group IV

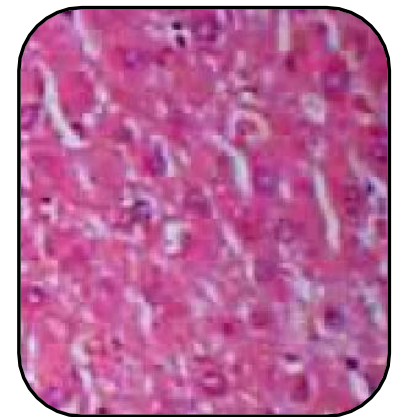

Group VII

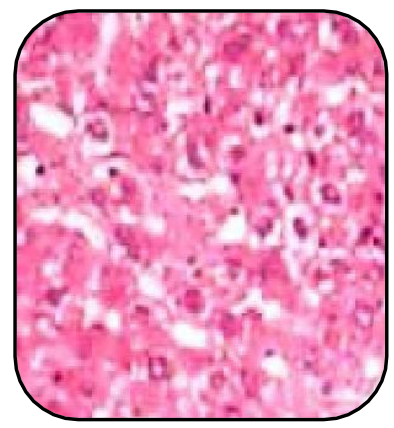

Group V

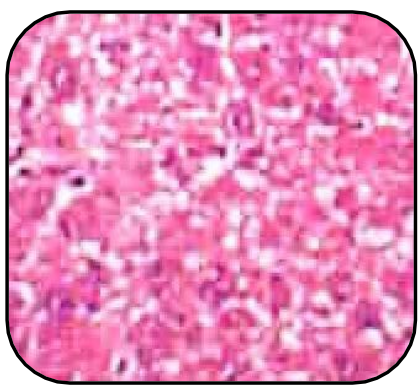

Group VIII

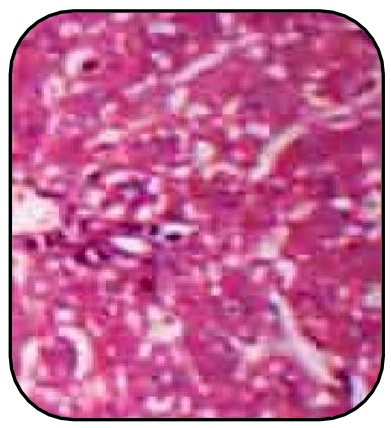

Group VI

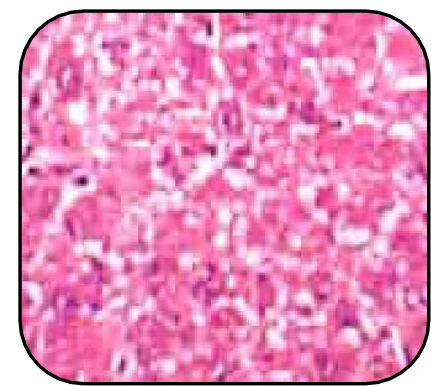

Group IX

References

[1]. Wolf P.L. Biochemical diagnosis of liver diseases. Indian Journal of Clinical Biochemistry 1999. 14, 59-90.

[2]. Friedman, Scott E, Grendell, James H, Quaid Mc, Kenneth R. Current diagnosis \& treatment in gastroenterology. New York: Lang Medical Books/McGraw-Hill, 2003:664.

[3]. McNally, Peter F. GI/Liver Secrets: with Student Consult Access. Saint Louis: C.V. Mosby.

[4]. Ostapowicz G, Fontana RJ, Schiqdt FV, et.al. Results of a prospective study of acute liver failure at 17 tertiary care centers in the United States. Ann. Intern. Med. 2002; 137: 947.

[5]. Bohlman, F., Knoll, K.-H., El-Emary, N.A. Newartige sesquiterpene lactone aus Pulicaria crispa. Phytochemistry. 1979; 18: 12311233 .

[6]. [20] Rustaiyan, A., Simozar, E., Ahmadi, A., Grenz, M., Bohlmann, F. A hardwickiic acid derivative from Pulicaria ghaphalodes. Phytochemistry. 1981; 20: 2772-2773.

[7]. Rai S, Wahile A, Mukherjee K, Saha BP, Mukherjee PK. (2006) Antioxidant activity of Nelumbo nucifera (sacred lotus) seeds. J. Ethnopharmacol. 104, 322-327.

[8]. Bergmeyer H.U, Gowehn K, and Grassel H. Methods of Enzymatic Analysis, ed. H.U. Bergmeyer, Weinheim: Verlag Chemine; 1974. 22. 438-9.

[9]. Hafemann DG, Sunde RA, Houestra WG. Effect of dietary selenium on erythrocyte and liver glutathione peroxidase in the rat. J. Nutr. 1974 104, 580- 584

[10]. Carlberg I, Mannervik B. Glutathione reductase levels in rat brain. J. Biol Chem. 1975. 250, 5475- 5479.

[11]. Lowry O.H, Rosebrough N.J, Farr A.L, and Randall R.J. Protein measurement with the folin phenol reagent. Journal of Biological Chemistry; 1951, 193: 265-75.

[12]. Strate T, Mann O, Kleighans H, Rusani S, Schneider C, Yekebas E, Freitag M, Standi T, Bloechle C, Izbicki J.R. Micro circulatory function and tissue damage is improved after the repeutic injection of bovine hemoglobin in server acute rodent pancreatitis. Pancreas; 2005, 30 (3):254-259.

[13]. Nadkarni KM. Indian Material Media. With Ayurvedic, unanitibbi, siddha, allopathic, homeopathic, naturopathic and home remedies, appendices and indexes, volume $1 \& 2$.Bombay popular prakashan PVT, LTD; 1976.

[14]. Reitman S, Frankel SA. Colorimetric method for the determination of serum oxaloacetatic and glutamic pyruvic transaminases. Am J .Clin Patho; 1957. 28, 56-63.

[15]. Reyes-Gordillo K, Segovia J, Shibayama M, Vergara P, Moreno MG, Muriel P. Curcumin protects against acute liver damage in the rat by inhibiting NF-KB, proinflammatory cytokines production and oxidative stress. Biochem Biophysic Acta 2007; 1770:989-96.

[16]. Dahlin D, Miwa G, Lee A. N-acetylpbenzoquinonamine: cytochrome P450 dependent oxidation product of acetaminophen. Proc Natl Acad Sci U S A 1984; 81: 327-331.

[17]. Recknagel RO, Glende EA, Dolk JA, Waller RL. Mechanism of carbon tetrachloride toxicity. Pharmacologic Therp; 1989. 43:13954.

[18]. Friedman, Scott E, Grendell, James H, Quaid Mc, Kenneth R. Current diagnosis \& treatment in gastroenterology. New York: Lang Medical Books/McGraw-Hill, 2003:664. 